\title{
Effect of Ultraviolet-B Irradiation on Disease Development Caused by Penicillium italicum in Satsuma Mandarin Fruit
}

\author{
Ittetsu Yamaga $^{1 *}$, Takeshi Kuniga ${ }^{2}$, Shinichi Aoki ${ }^{3}$, Mitsuhiro Kato ${ }^{1}$ \\ and Yasushi Kobayashi ${ }^{1}$
}

\author{
${ }^{1}$ Fruit Tree Research Center, Shizuoka Prefectural Agriculture and Forestry Research Institute, Shizuoka 424-0905, Japan \\ ${ }^{2}$ NARO Western Region Agricultural Research Center, Zentsuji 765-0053, Japan \\ ${ }^{3}$ Panasonic Corporation, Kadoma 571-8686, Japan
}

Blue mold (Penicillium italicum) is the primary postharvest pathogen affecting citrus fruit. In the present study, we investigated the effect of ultraviolet (UV-B) irradiation on blue mold, and the influence of UV-B on the internal fruit quality and peel color of satsuma mandarin. All UV-B doses examined $(15,30,60$, and $120 \mathrm{~kJ} \cdot \mathrm{m}^{-2}$ ) had inhibitory effects on P. italicum growth in vitro (reduction of spore germination $>99 \%$ ). Additionally, we examined the disease incidence, the soft rot (water soaked) area diameter, and the mycelium (mycelial growth inside soft rot area) area diameter of Citrus unshiu Marc. 'Aoshima unshu', which was treated by UV-B irradiation $24 \mathrm{~h}$ before or after inoculation at two different harvest periods. The diameter and incidence of soft rot areas were not significantly reduced by UV-B irradiation at 5 days after inoculation. However, a UV-B dose of $60 \mathrm{~kJ} \cdot \mathrm{m}^{-2}$ reduced the diameter of mycelial growth on fruit for 5 days after inoculation, at both early and commercial harvests. At early harvest, UV-B irradiation at doses of $30 \mathrm{~kJ} \cdot \mathrm{m}^{-2}$ and $60 \mathrm{~kJ} \cdot \mathrm{m}^{-2}$ was effective at reducing the incidence of mycelial growths, regardless of whether irradiation occurred $24 \mathrm{~h}$ before inoculation or whether inoculation occurred immediately prior to UV-B irradiation. UVB irradiation did not affect fruit quality with respect to soluble solid concentration, titratable acidity, or peel color. Although UV-B irradiation did not significantly control disease development in inoculated fruit, our results indicate that it might be effective by directly inactivating fungi and inducing an antifungal response in satsuma mandarin fruit.

Key Words: citrus, fruit decay, fruit quality, mycelium area.

\section{Introduction}

The postharvest decay of citrus fruit is caused by Penicillium italicum, P. digitatum, Botrytis cinerea, and other fungi, and is a source of economic loss for organizations involved in the cultivation, export, and sale of citrus fruit. Blue mold (P. italicum) is the most economically important pathogen affecting satsuma mandarin fruit. In Japan, citrus fruit decay is controlled by the application of chemical fungicides to trees prior to harvesting. However, their use has gradually become more limited owing to rising public concerns over both health and environmental issues, including the development of fungal resistance. Alternative methods of postharvest

Received; May 7, 2015. Accepted; July 29, 2015.

First Published Online in J-STAGE on September 4, 2015.

* Corresponding author (E-mail: ittetsu1_yamaga@pref.shizuoka. $\lg . j p)$. disease management are expected to facilitate a reduction in the application of chemical fungicides. Ultraviolet-C (UV-C) radiation, heat treatment, application of sodium bicarbonate, and other methods have been assessed as potential alternatives to fungicide application (Arimoto et al., 1977; Cerioni et al., 2012; Kim et al., 1991; Kinay et al., 2005). Rodov et al. (1992) have described that exposure to UV-C light increases the production of phytoalexins such as scoparone (6,7-dimethoxycoumarin) and scopoletin (7hydroxy-6-methoxycoumarin) in the peel of citrus fruit, a response that is associated with induced resistance to postharvest decay. They demonstrated that kumquat fruit treated with exposure to UV-C light $48 \mathrm{~h}$ prior to inoculation with P. digitatum exhibited reduced decay rates relative to those of untreated fruit. However, another study showed that UV-C irradiation caused significant damage (such as browning) to citrus peel when used at higher doses (D'hallewin et al., 1999). Alter- 
natively, the induction of disease resistance via UV-B irradiation has been investigated extensively in many horticultural crops, with several researchers suggesting that UV-B irradiation-induced defenses in model plants are developed in response to the presence of reactive oxygen species and pathogens (Costa et al., 2013; Demkura et al., 2012; Green and Fluhr, 1995). Arimoto et al. (2014) reported that $3 \mathrm{~h}$ of nighttime UV-B irradiation with a fluency of $10 \mu \mathrm{W} \cdot \mathrm{cm}^{-2}$ reduced the incidence of powdery mildew when applied to strawberries during cultivation. However, little information is available concerning the effect of UV-B irradiation on the postharvest fungal decay of citrus fruit. The aim of this study was thus to investigate the potential use of UV-B irradiation to control blue mold growth in satsuma mandarin fruit. We examined the effects of different doses of UV-B irradiation in vitro on the suppression of blue mold growth, and investigated symptom development and disease incidence in mold-inoculated fruit irradiated with two different intensities of UV-B radiation. We subsequently investigated the influence of UV-B irradiation on both internal fruit quality and rind color.

\section{Materials and Methods}

\section{Suppression of postharvest fungal growth by $U V-B$ irradiation in vitro}

Penicillium italicum and P. digitatum were obtained from infected citrus fruit at the Shizuoka Prefectural Agriculture and Forestry Research Institute's Fruit Tree Research Center, and cultured on potato dextrose agar (PDA; $39 \mathrm{~g} \cdot \mathrm{L}^{-1}$ ) at $25^{\circ} \mathrm{C}$ in the dark. A suspension was prepared by removing spores from the sporulating zone of 7-day-old cultures and suspending them in sterile distilled water containing $0.1 \%$ Triton X-100. Spore concentration was adjusted to $1 \times 10^{3}$ spores per $\mathrm{mL}$ using a hemocytometer, and $200 \mu \mathrm{L}$ of suspension was applied to a Petri dish containing PDA. The Petri dishes were irradiated using UV-B lamps with peak emission at $310 \mathrm{~nm}$ (YGRFX21711GL; Panasonic Corporation, Osaka, Japan). UV-B irradiance was measured using a UV digital radiometer (UV-340C; Custom, Tokyo, Japan), and the irradiation time was varied to achieve the desired UV-B doses (no irradiation, 15, 30, 60, and $120 \mathrm{~kJ} \cdot \mathrm{m}^{-2}$ ). The Petri dishes without a lid were placed $15 \mathrm{~cm}$ from the irradiation source. To determine the effect of UV-B irradiation on in vitro fungal growth, treated dishes covered with a plastic lid were cultured at $20^{\circ} \mathrm{C}$ for $48 \mathrm{~h}$ in the dark, after which the number of colony forming units per dish was counted.

\section{Effect of $U V-B$ irradiation on blue mold fungal de- velopment in satsuma mandarin fruit}

Satsuma mandarin (Citrus unshiu Marc.) fruit of the cultivar 'Aoshima unshu' (late-maturing cultivar, harvest period: late November to mid-December) were harvested from an orchard at the Shizuoka Prefectural Agriculture and Forestry Research Institute's Fruit Tree
Research Center on October 30 (early harvest) and November 20 (commercial harvest), 2014. A suspension of P. italicum was prepared as described above, and the spore concentration was adjusted to $1 \times 10^{5}$ spores per $\mathrm{mL}$ using a hemocytometer. Two 2-mmdeep $\times 1$-mm-diameter incisions were made between the pedicel and lateral part of one fruit, using a needle equipped with a stopper to ensure wound uniformity. Then, $3 \mu \mathrm{L}$ of the suspension was applied to the wound with a precision pipette. The fruit were irradiated with UV-B at doses of $30 \mathrm{~kJ} \cdot \mathrm{m}^{-2}$ and $60 \mathrm{~kJ} \cdot \mathrm{m}^{-2}$. The fruit were placed $15 \mathrm{~cm}$ from the irradiation source. UV-B irradiation was performed at, before ( $24 \mathrm{~h}$ prior), or immediately after wounding and inoculation. Nonirradiated fruit were prepared as a control. The treated fruit were kept for 5 days in a chamber with $85 \%-90 \%$ relative humidity $(\mathrm{RH})$ at $20^{\circ} \mathrm{C}$. The diameters of the soft rot (water soaked) area and mycelium (mycelial growth inside soft rot area) area were measured with a ruler according to the methods described in a previous study (Yamaga et al., 2015), at 4 and 5 days after treatment. The diameter of these areas was set as the average of the long and short lengths. The diameter of non-infected fruit was calculated as 0 . Infected fruit were counted, and the disease incidence was calculated according to the following formula:

Disease incidence $=$ (number of fruit on which a fungal area occurred/total number of examined fruit) $\times 100$

Each treatment consisted of six replicates of five fruit each, in a completely randomized design.

\section{Influence of $U V-B$ irradiation on internal fruit quali- ty and rind color}

Five replicates of five fruit ('Aoshima unshu') each were randomly selected, and the fruit were irradiated with UV-B at a dose of $60 \mathrm{~kJ} \cdot \mathrm{m}^{-2}$, as described above. Non-irradiated fruit were used as a control. After UV irradiation, the fruit were kept in the dark at $20^{\circ} \mathrm{C}$ for 10 days. Specific gravity was determined by weighing fruit in air and water. Percentage of flesh was calculated by using the ratio of flesh to whole fruit weight. The degree of peel puffing was rated as $0,1,2$, and 3 according to Shiraishi et al. (1999). The soluble solid concentration (SSC) and titratable acidity (TA) were determined using freshly extracted juice. The SSC was determined using a digital refractometer (DBX-55A; Atago, Tokyo, Japan). The TA was determined by titrating $5 \mathrm{~mL}$ of the juice to $\mathrm{pH} 8.1$, with $0.156 \mathrm{~mol} \cdot \mathrm{L}^{-1}$ $\mathrm{NaOH}$. The acidity of the juice is expressed as $\mathrm{g}$ of citric acid per $100 \mathrm{~mL}$ of juice. Rind color was measured using a colorimeter (TC-1500SX; Tokyo Denshoku, Tokyo, Japan). The CIELAB (L*=lightness, $\mathrm{a}^{*}=$ bluish-green/red purple hue component, $b^{*}=$ yellow/ blue hue component) of the rinds was measured and chroma $\left(\mathrm{C}^{*}\right)$ values were calculated. 


\section{Statistical analysis}

Statistical analysis was performed using statistical functions in Microsoft Office Excel 2007 for Windows (Microsoft Corporation, Redmond, WA, USA). The difference between the means was evaluated by Student's $t$-test or Tukey's multiple range test.

\section{Results}

1. Suppression of postharvest fungal growth by $U V-B$ irradiation in vitro

All examined UV-B doses $(15,30,60$, and $120 \mathrm{~kJ} \cdot \mathrm{m}^{-2}$ ) inactivated the conidia of P. italicum in vitro (Fig. 1). UV-B irradiation at $15 \mathrm{~kJ} \cdot \mathrm{m}^{-2}$ reduced the number of colony forming units by $99 \%$ after $48 \mathrm{~h}$ of incubation. In addition, 30,60 , and $120 \mathrm{~kJ} \cdot \mathrm{m}^{-2} \mathrm{UV}$-B irradiation inactivated virtually all conidia. UV-B irradiation also had a strong inhibitory effect on $P$. digitatum growth in vitro.

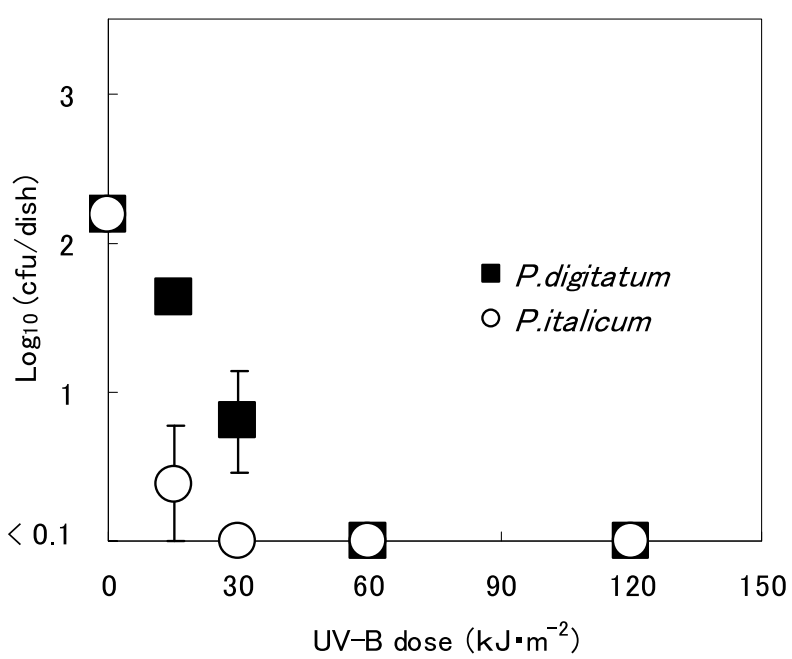

Fig. 1. Effect of UV-B irradiation on the spore germination of P. italicum and P. digitatum in vitro. Vertical bars indicate SE $(\mathrm{n}=4)$.
2. Effect of UV-B irradiation on the disease incidence and the fungal development of blue mold on satsuma mandarin fruit

As shown in Table 1, at early harvest, UV-B irradiation at 30 and $60 \mathrm{~kJ} \cdot \mathrm{m}^{-2}$ doses prior to inoculation was effective at reducing the disease incidence of soft rot at 4 days after inoculation, as the mycelium area was not clearly developed by day 4 after inoculation. At 5 days after inoculation, UV-B irradiation was not effective at reducing the disease incidence of the soft rot area. However, UV-B irradiation at doses of $30 \mathrm{~kJ} \cdot \mathrm{m}^{-2}$ and $60 \mathrm{~kJ} \cdot \mathrm{m}^{-2}$ was effective at reducing the incidence of fungal mycelia, regardless of whether irradiation was applied $24 \mathrm{~h}$ before inoculation or whether inoculation was conducted immediately prior to UV-B irradiation. On the other hand, it was not effective at preventing the infection of fruit harvested during the commercial period.

Diameters of blue mold fungal growths on earlyharvest satsuma mandarin fruit at 5 days after inoculation are shown in Figure 2. The diameter of the soft rot area was not significantly different between the UVBtreated and untreated fruit. UV-B applied at a dosage of $60 \mathrm{~kJ} \cdot \mathrm{m}^{-2}$ reduced mycelium diameters significantly in both fruit treated before inoculation and those treated after it. The smallest mycelium diameter was observed in the $60 \mathrm{~kJ} \cdot \mathrm{m}^{-2} \mathrm{UV}-\mathrm{B}+$ inoculation treatment, followed by inoculation $+60 \mathrm{~kJ} \cdot \mathrm{m}^{-2} \mathrm{UV}-\mathrm{B}$, inoculation + $30 \mathrm{~kJ} \cdot \mathrm{m}^{-2} \mathrm{UV}-\mathrm{B}, 30 \mathrm{~kJ} \cdot \mathrm{m}^{-2} \mathrm{UV}-\mathrm{B}+$ inoculation, and the control. At 5 days after inoculation, the reductions in mycelium area for the $60 \mathrm{~kJ} \cdot \mathrm{m}^{-2} \mathrm{UV}-\mathrm{B}+$ inoculation and inoculation $+60 \mathrm{~kJ} \cdot \mathrm{m}^{-2} \mathrm{UV}-\mathrm{B}$ treatments were $80 \%$ and $75 \%$, respectively, compared with the control. The diameters of blue mold fungal growths at commercial harvest are presented in Figure 3. The diameter of the soft rot area was not significantly different among treatments for fruit at early harvest. On the other hand, the mycelium area with the smallest diameter was observed in the $60 \mathrm{~kJ} \cdot \mathrm{m}^{-2} \mathrm{UV}-\mathrm{B}+$ inoculation treatment, followed by inoculation $+60 \mathrm{~kJ} \cdot \mathrm{m}^{-2} \mathrm{UV}-\mathrm{B}, 30 \mathrm{~kJ} \cdot \mathrm{m}^{-2} \mathrm{UV}-$ $\mathrm{B}+$ inoculation, inoculation $+30 \mathrm{~kJ} \cdot \mathrm{m}^{-2} \mathrm{UV}-\mathrm{B}$, and the

Table 1. Effect of UV-B irradiation on disease incidence caused by P. italicum infections of satsuma mandarin fruit.

\begin{tabular}{|c|c|c|c|c|c|c|c|c|}
\hline \multirow{4}{*}{ UV-B dose } & \multicolumn{8}{|c|}{ Disease incidence (\%) } \\
\hline & \multicolumn{4}{|c|}{ Early harvest } & \multicolumn{4}{|c|}{ Commercial harvest } \\
\hline & \multicolumn{2}{|c|}{ Soft rot area } & \multicolumn{2}{|c|}{ Mycelium area } & \multicolumn{2}{|c|}{ Soft rot area } & \multicolumn{2}{|c|}{ Mycelium area } \\
\hline & 4 day & 5 day & 4 day & 5 day & 4 day & 5 day & 4 day & 5 day \\
\hline $30 \mathrm{~kJ} \cdot \mathrm{m}^{-2}+$ Inoculation & $8.9 b^{z}$ & $20.0 \mathrm{a}$ & 0.0 & $6.7 \mathrm{~b}$ & $27.1 \mathrm{a}$ & $45.0 \mathrm{a}$ & 0.0 & $25.6 \mathrm{a}$ \\
\hline $60 \mathrm{~kJ} \cdot \mathrm{m}^{-2}+$ Inoculation & $8.9 \mathrm{~b}$ & $30.0 \mathrm{a}$ & 0.0 & $0.0 \mathrm{~b}$ & $25.1 \mathrm{a}$ & $45.0 \mathrm{a}$ & 0.0 & $27.8 \mathrm{a}$ \\
\hline Inoculation $+30 \mathrm{~kJ} \cdot \mathrm{m}^{-2}$ & $20.5 \mathrm{a}$ & $33.3 \mathrm{a}$ & 0.0 & $6.7 \mathrm{~b}$ & $33.7 \mathrm{a}$ & $43.8 \mathrm{a}$ & 0.0 & $32.8 \mathrm{a}$ \\
\hline Inoculation $+60 \mathrm{~kJ} \cdot \mathrm{m}^{-2}$ & $10.0 \mathrm{a}$ & $23.3 \mathrm{a}$ & 0.0 & $3.3 \mathrm{~b}$ & $25.4 \mathrm{a}$ & $48.8 \mathrm{a}$ & 0.0 & $25.1 \mathrm{a}$ \\
\hline Control (Inoculated) & $31.5 \mathrm{a}$ & $40.0 \mathrm{a}$ & 0.0 & $23.3 \mathrm{a}$ & $35.1 \mathrm{a}$ & $46.7 \mathrm{a}$ & 0.0 & $36.1 \mathrm{a}$ \\
\hline
\end{tabular}

${ }^{\mathrm{z}}$ Different letters indicate significant differences at $P<0.05$ by Tukey's multiple range test.

Data are expressed as the means $(n=6)$.

Data were transformed to the arcsine of the square root before analysis. 

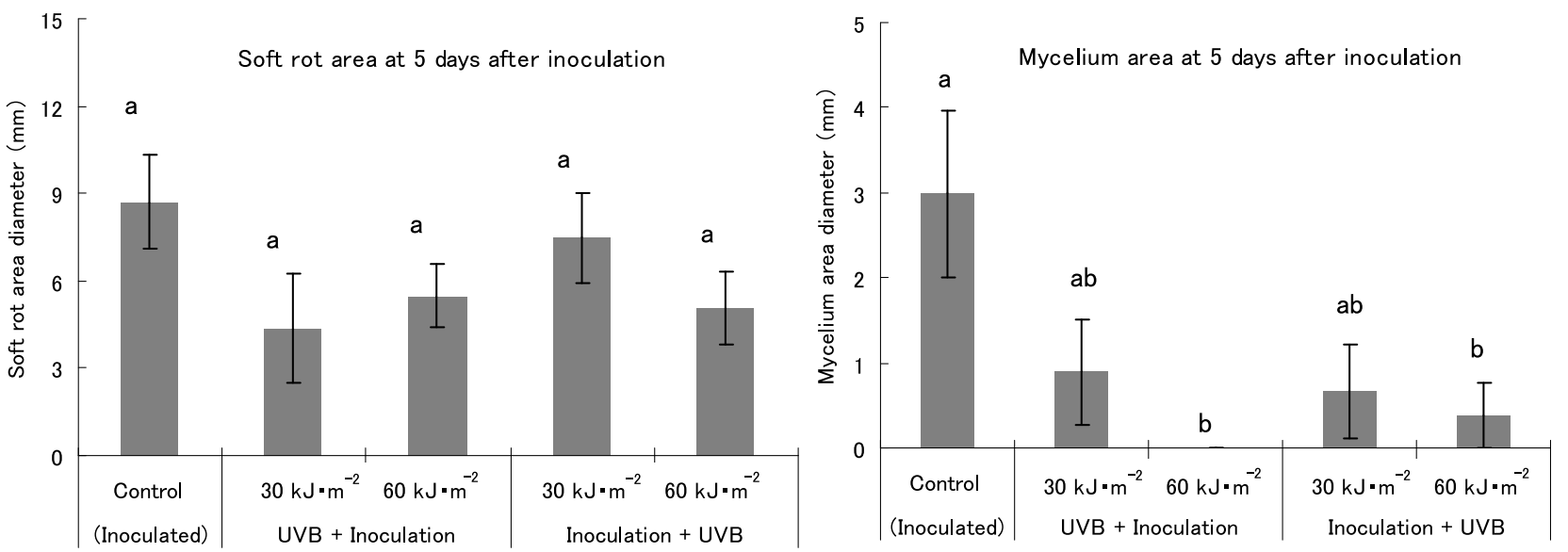

Fig. 2. Effect of UV-B irradiation on fruit fungal diameter caused by P. italicum in satsuma mandarin at early harvest (October). Vertical bars indicate SE $(\mathrm{n}=6)$. Different letters indicate significant differences at $P<0.05$ by Tukey's multiple range test. UVB + Inoculation: UV-B irradiation at $24 \mathrm{~h}$ before wounding and inoculation. Inoculation + UVB: UV-B irradiation immediately after wounding and inoculation.
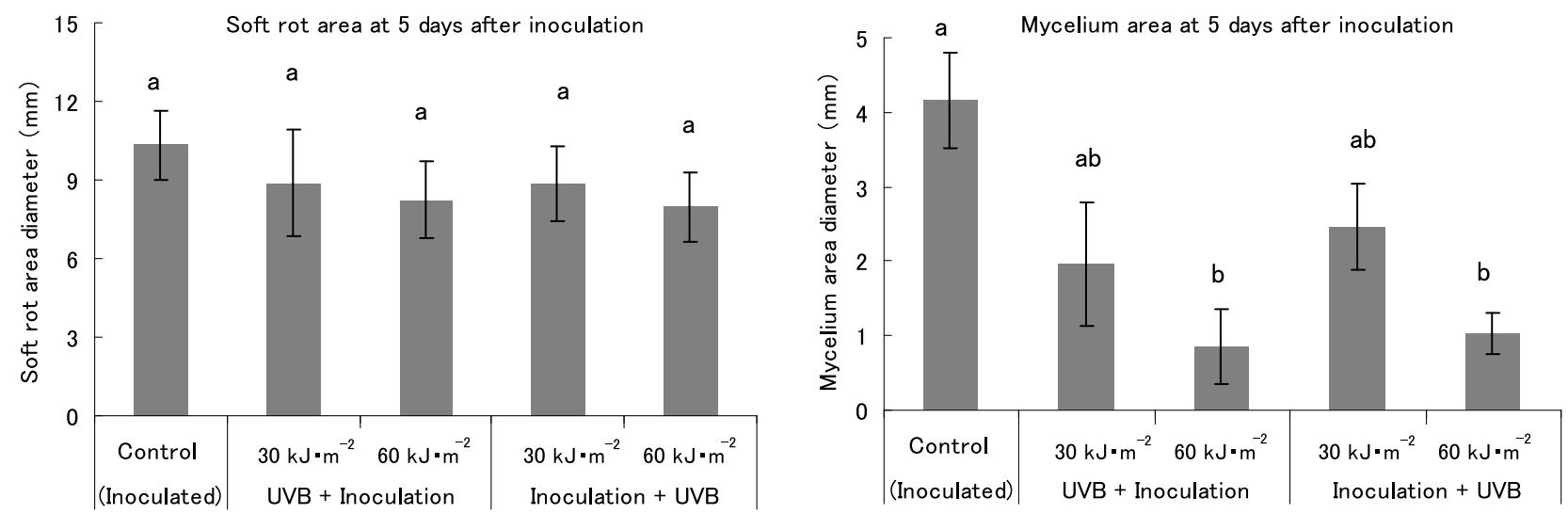

Fig. 3. Effect of UV-B irradiation on fruit fungal diameter caused by P. italicum infection of satsuma mandarin at commercial harvest (November). Vertical bars indicate SE $(\mathrm{n}=6)$. Different letters indicate the significant differences at $P<0.05$ by Tukey's multiple range test. UVB + Inoculation: UV-B irradiation at $24 \mathrm{~h}$ before wounding and inoculation. Inoculation + UVB: UV-B irradiation immediately after wounding and inoculation.

Table 2. Influence of UV-B irradiation on the fruit quality of satsuma mandarin (Citrus unshiu Marc. 'Aoshima unshu').

\begin{tabular}{lccccccc}
\hline \hline Treatment & $\begin{array}{c}\text { Average fruit } \\
\text { weight }(\mathrm{g})\end{array}$ & Specific gravity & $\begin{array}{c}\text { Percentage of } \\
\text { flesh }(\%)\end{array}$ & $\begin{array}{c}\text { Degree of peel } \\
\text { puffing }\end{array}$ & $\begin{array}{c}\text { SSC } \\
\left({ }^{\circ} \text { Brix }\right)\end{array}$ & $\begin{array}{c}\text { TA (g/100 mL as } \\
\text { citric acid) }\end{array}$ & SSC/TA \\
\hline UVB & 144 & 0.90 & 79.5 & 0.2 & 12.0 & 0.76 & 16.0 \\
Control & 136 & 0.89 & 78.5 & 0.2 & 12.0 & 0.79 & 15.3 \\
Significance $^{\mathrm{z}}$ & - & $\mathrm{NS}$ & $\mathrm{NS}$ & $\mathrm{NS}$ & $\mathrm{NS}$ & $\mathrm{NS}$ & $\mathrm{NS}$ \\
\hline
\end{tabular}

${ }^{\mathrm{z}} \mathrm{NS}$ : not significant; - : not analyzed.

Data are expressed as the means of 5 replicates.

control. Mycelium area was significantly reduced relative to the control by $60 \mathrm{~kJ} \cdot \mathrm{m}^{-2} \mathrm{UV}-\mathrm{B}$ irradiation, regardless of whether the treatment was applied prior to or after inoculation.

\section{Influence of UV-B irradiation on internal fruit quali- ty and rind color}

The influences of UV-B irradiation on the internal fruit quality and rind color of satsuma mandarins are shown in Table 2 and Table 3, respectively. Irradiation
Table 3. Influence of UV-B irradiation on the rind color of satsuma mandarin (Citrus unshiu Marc. 'Aoshima unshu').

\begin{tabular}{lcccc}
\hline \hline \multirow{2}{*}{ Treatment } & \multicolumn{4}{c}{ Rind color } \\
\cline { 2 - 5 } & $\mathrm{L}^{*}$ & $\mathrm{a}^{*}$ & $\mathrm{~b}^{*}$ & $\mathrm{C}^{*}$ \\
\hline UVB & 63.8 & 22.5 & 65.1 & 68.9 \\
Control & 63.8 & 22.2 & 64.2 & 68.1 \\
Significance $^{\mathrm{z}}$ & $\mathrm{NS}$ & $\mathrm{NS}$ & $\mathrm{NS}$ & $\mathrm{NS}$ \\
\hline
\end{tabular}

${ }^{z}$ NS: not significant.

Data are expressed as the means of 5 replicates. 
with a UV-B dose of $60 \mathrm{~kJ} \cdot \mathrm{m}^{-2}$ did not influence either the fruit quality characteristics analyzed in this study (SSC, TA, specific gravity, percentage of flesh, and peel puffing) or the rind color, as evaluated by the coefficient $\left(\mathrm{L}^{*}\right), \mathrm{a}^{*}$ value, $\mathrm{b}^{*}$ value, and chroma $\left(\mathrm{C}^{*}\right)$.

\section{Discussion}

All UV-B doses examined (15, 30, 60, and $120 \mathrm{~kJ} \cdot \mathrm{m}^{-2}$ ) in this study had high inhibitory effects on $P$. italicum growth in vitro (reduction of spore germination $>99 \%$ ). Our data indicate that UV-B irradiation can control the spore germination of P. italicum and P. digitatum in vitro, even at low doses. Hamamoto et al. (2007) examined the differences in the damage to bacterial DNA caused by UVA-LED $(365 \mathrm{~nm})$ and UVC $(254 \mathrm{~nm})$ treatments. They concluded that the formation of the cyclobutane pyrimidine dimer, which is an indicator of direct DNA damage by UV-C irradiation, and 8-hydroxy-2'-deoxyguanosine, which is an indicator of oxidative damage, was produced by treatment with UVA-LED. Although a filamentous fungus is stronger than bacteria, the mechanism behind the inactivation of Penicillium by UV-B irradiation could also be a result of either direct or oxidative DNA damage.

UV-B irradiation could not control the incidence of soft rot disease in inoculated satsuma mandarin fruit harvested at two different periods. The effect of irradiation was limited to suppression of mycelium growth (at early and commercial harvests) and the incidence of fungal mycelia (only at early harvest). The inefficacy of UV-B irradiation in controlling disease incidence could be attributed to the period between UV-B irradiation and inoculation, and the inoculation density of the pathogen. The length of the period between UV-B irradiation and inoculation might influence the induction of disease resistance as UV-C irradiation does. At early harvest, UV-B irradiation $24 \mathrm{~h}$ prior to inoculation reduced the incidence of soft rot and mycelium growth, and suppressed the growth of areas of mycelia, relative to the fruit treated with UV-B irradiation only after inoculation. Rodov et al. (1992) reported that the production of the phytoalexin scoparone reached a maximum in kumquat fruit flavedo at 11 days after treatment with UV-C, and then declined to trace levels 1 month after irradiation. On the other hand, the concentration of inoculated fungi may be related to the development of fungal area and disease incidence. Mercier et al. (2001) described that enough inoculum to initiate infection could remain, even if UV irradiation could kill a significant proportion of the fungal propagules. UV-C had a strong germicidal effect on Botrytis cinerea, killing most of the exposed spores on agar and fruit wounds; however, it was ineffective at preventing the infection of fruit that had been inoculated $24 \mathrm{~h}$ prior to irradiation (Mercier et al., 2001). Previously, we reported that suppression of blue mold fungal development in satsuma mandarin fruit treated by blue light-emitting diode
(LED) irradiation differed relative to the concentration of the fungal inoculum (Yamaga et al., 2015).

Our results indicate that the response of satsuma mandarin fruit to UV-B irradiation differed according to the harvest date. Similarly, D'hallewin et al. (1999) reported that 'Washington Navel', 'Biondo Comune', and 'Tarocco' fruit, which are harvested late in the season, exhibit higher decay rates than those harvested early. Additionally, they reported that the fruit harvested earlier had higher scoparone content induced by UV-C treatment than the fruit harvested late. Previous studies and our results suggest that induced resistance is an important component of decay control. In order to clarify the effect of UV-B irradiation, it is necessary to test the possibility of controlling fruit decay due to natural infections, via UV-B irradiation of non-inoculated fruit.

Early-maturing cultivars in citrus species tend to accumulate low concentrations of scoparone, which is associated with resistance to fruit decay by UV-C irradiation compared with that of late-maturing species (Kuniga et al., 2005). We also observed scoparone accumulation in the flavedo of early-maturing satsuma mandarin cultivar by UV-B irradiation (data not shown), so the production of scoparone in late-maturing cultivars such as 'Aoshima unshu' would also observed by UV-B irradiation. Kuniga et al. (2005) reported that the duration of the change in scoparone synthesis differs among growth phases and citrus varieties. Considering the results of a previous study investigating induced fungal resistance (Kim et al., 1991; Ortuño et al., 2011), it appears that scoparone accumulated continuously until about 10 days after UV treatment, and that the production of other phytoalexins might be induced by UV irradiation. Ortuño et al. (2006) revealed that some flavonoids isolated from citrus fruit reduce the radial growth of P. digitatum when added to PDA culture medium. Therefore, the quantity of phytoalexins induced by UV irradiation might differ according to maturity and time spent in storage. Studies are needed to clarify the relationship between scoparone content and fruit maturity, or the changes in scoparone content induced by UV-B irradiation.

UV-B irradiation did not affect the SSC, TA, degree of peel puffing, specific gravity, percentage of flesh, or rind color of treated fruit. Thus, according to our study, UV-B irradiation resulted in no visible damage to the fruit of the satsuma mandarin cultivar 'Aoshima unshu'. D'hallewin et al. (1999) reported that there were no differences between the internal fruit quality characteristics of UV-C-treated and -untreated fruit from various citrus cultivars; however, UV-C irradiation caused varying degrees of visible damage to the fruit, in the form of rind browning and tissue necrosis. According to our results, it appears that, in contrast to UV-C irradiation, UV-B irradiation does not damage mandarin fruit, even at high doses. However, Kaewsuksaeng et al. (2011) reported that UV-B treatment induces a gradual increase 
in citric acid formation and suppresses the increase of sugar content in lime (Citrus latifolia Tan.) fruit during storage. The influence of UV-B irradiation on citric acid and sugar contents appears to vary among cultivars and maturity stages.

This result showed that UV-B irradiation did not significantly reduce the disease incidence and the fungal development of blue mold on inoculated fruit. On the other hand, this work indicated the possibility of using UV-B irradiation at a dose of $60 \mathrm{~kJ} \cdot \mathrm{m}^{-2}$ for controlling mycelial growth of blue mold in satsuma mandarin. However, this study did not elucidate the detailed mechanism of the antifungal response of satsuma mandarin. Additionally, we did not determine that UV-B irradiation induced the production of phytoalexin in flavedo tissue, as did UV-C irradiation. Further studies utilizing both biochemical and molecular approaches are required in order to evaluate the relationship among UV-B irradiation, host response, and the suppression of fungal growth. As described above, we need to verify the ability of UV-B irradiation to control fruit decay due to naturally occurring infections using non-inoculated mandarins. A problem associated with utilizing the application of UV light on citrus fruit in commercial applications is to ensure dose uniformity at the packing house. Yan et al. (2014) demonstrated that 1/3 of irradiated apricots had portions of surface area receiving less than $0.2 \mathrm{~kJ} \cdot \mathrm{m}^{-2} \mathrm{UV}-\mathrm{C}$ radiation, even though the fruit received an average dose of $1 \mathrm{~kJ} \cdot \mathrm{m}^{-2}$ in a commercial setting. Finally, the practical application of UV irradiation in actual grading and packing lines should also be considered.

\section{Literature Cited}

Arimoto, M., M. Hasebe, M. Yamada, S. Aoki and Y. Enami. 2014. Controlling effects against powdery mildew on strawberries by UV-B night radiation. Ann. Rept. Kansai Pl. Prot. 56: 75-76 (In Japanese).

Arimoto, Y., Y. Homma and T. Misato. 1977. The effect of sodium hydrogencarbonate on the occurrence of citrus storage diseases. J. Pestic. Sci. 2: 163-167.

Cerioni, L., L. Rodriguez-Montelongo, J. Ramallo, F. E. Prado, V. A. Rapisarda and S. I. Volentini. 2012. Control of lemon green mold by a sequential oxidative treatment and sodium bicarbonate. Postharvest Biol. Technol. 63: 33-39.

Costa, L., D. Rangel, M. Morandi and W. Bettiol. 2013. Effects of UV-B radiation on the antagonistic ability of Clonostachys rosea to Botrytis cinerea on strawberry leaves. Biol. Control 65: $95-100$

Demkura, P. V. and C. L. Ballare. 2012. UVR8 mediates UV-Binduced Arabidopsis defense responses against Botrytis cinerea by controlling sinapate accumulation. Mol. Plant 5: 642-652.
D’hallewin, G., M. Schirra and E. Manueddu. 1999. Scoparone and scopoletin accumulation and ultraviolet-C induced resistance to postharvest decay in oranges as influenced by harvest date. J. Amer. Soc. Hort. Sci. 124: 702-707.

Green, R. and R. Fluhr. 1995. UV-B-induced PR-1 accumulation is mediated by active oxygen species. Plant Cell 7: 203-212.

Hamamoto, A., M. Mori, A. Takahashi, M. Nakano, N. Wakikawa, M. Akutagawa, T. Ikehara, Y. Nakaya and Y. Kinouchi. 2007. New water disinfection system using UVA light-emitting diodes. J. Appl. Microbiol. 103: 2291-2298.

Kaewsuksaeng, S., Y. Urano, S. Aiamla-or, M. Shigyo and N. Yamaguchi. 2011. Effect of UV-B irradiation on chlorophylldegrading enzyme activities and postharvest quality in stored lime (Citrus latifolia Tan.) fruit. Postharvest Biol. Technol. 61: 124-130.

Kim, J. J., S. B. Yehoshua, B. Shapiro, Y. Henis and S. Carmeli. 1991. Accumulation of scoparone in heat-treated lemon fruit inoculated with Penicillium digitatum Sacc. Plant Physiol. 97: 880-885.

Kinay, P., F. Yildiz, F. Sen, M. Yildiz and I. Karacali. 2005. Integration of pre- and postharvest treatments to minimize Penicillium decay of satsuma mandarins. Postharvest Biol. Technol. 37: 31-36.

Kuniga, T., Y. Matsuo, T. Tsumura, K. Kojima and R. Matsumoto. 2005. Production of phytoalexin, scoparone in citrus cultivars following treatment with UV radiation. Hort. Res. (Japan) 4: 99-103 (In Japanese with English abstract).

Mercier, J., M. Baka, B. Reddy, R. Corcuff and J. Arul. 2001. Shortwave ultraviolet irradiation for control of decay caused by Botrytis cinerea in bell pepper: induced resistance and germicidal effects. J. Amer. Soc. Hort. Sci. 126: 128-133.

Ortuño, A., A. Báidez, P. Gómez, M. C. Arcas, I. Porras, A. García-Lidón and J. A. Del Rio. 2006. Citrus paradisi and Citrus sinensis flavonoids: their influence in the defence mechanism against Penicillium digitatum. Food Chem. 98: 351-358.

Ortuño, A., L. Díaz, N. Alvarez, I. Porras, A. García-Lidón and J. A. Del Rio. 2011. Comparative study of flavonoid and scoparone accumulation in different Citrus species and their susceptibility to Penicillium digitatum. Food Chem. 125: 232-239.

Rodov, V., S. B. Yehoshua, J. J. Kim, B. Shapiro and Y. Ittah. 1992. Ultraviolet illumination induces scoparone production in kumquat and orange fruit and improves decay resistance. J. Amer. Hort. Sci. 117: 788-792.

Shiraishi, M., P. Mohammad, Y. Makita, M. Fujibuchi and T. Manabe. 1999. Effects of calcium compounds on fruit puffing and the ultrastructural characteristics of the subepidermal cell walls of puffy and calcium-induced non-puffy satsuma mandarin fruits. J. Japan. Soc. Hort. Sci. 68: 919-926.

Yamaga, I., T. Takahashi, K. Ishii, M. Kato and Y. Kobayashi. 2015. Antifungal effect of blue LED irradiation on the blue mold, Penicillium italicum, in satsuma mandarin fruits. Hort. Res. (Japan) 14: 83-87 (In Japanese with English abstract).

Yan, R., J. Mattheis, J. Gurtlera, J. Sitesa and X. Fan. 2014. UV-C inactivation of Escherichia coli and dose uniformity on apricotfruit in a commercial setting. Postharvest Biol. Technol. 95: 46-49. 